\title{
Development of Prediction Model for Storm Surge Hazards in the Developing Countries ${ }^{\dagger}$
}

\author{
Hasibun Naher ${ }^{1, *}$ and Gour Chandra Paul ${ }^{2}$ \\ 1 Department of Mathematics and Natural Sciences, Brac University, 66 Mohakhali, Dhaka 1212, Bangladesh \\ 2 Department of Mathematics, University of Rajshahi, Rajshahi 6205, Bangladesh; pcgour2001@yahoo.com \\ * Correspondence: hasibun06tasauf@gmail.com; Tel.: +88-01818182462 \\ + Presented at the 3rd International Electronic Conference on Geosciences, 7-13 December 2020; \\ Available online: https://iecg2020.sciforum.net.
}

Citation: Naher, H.; Paul, G.C. Development of Prediction Model for Storm Surge Hazards in the Developing Countries. Environ. Sci. Proc. 2021, 5, 7. https://doi.org/ 10.3390/IECG2020-08630

Academic Editor: Jesus Martinez Frias

Published: 30 November 2020

Publisher's Note: MDPI stays neutral with regard to jurisdictional claims in published maps and institutional affiliations.

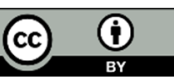

Copyright: $(2) 2020$ by the authors. Licensee MDPI, Basel, Switzerland. This article is an open access article distributed under the terms and conditions of the Creative Commons Attribution (CC BY) license (http://creativecommons.org/licenses/by/4.0/).

\begin{abstract}
Bangladesh is one of the most vulnerable countries in the world with around 718,000 deaths in the past fifty years. This country is especially in danger for cyclones because of its location in the triangular-shaped Bay of Bengal. The scientific scenario suggests that enlarged sea surface temperature will intensify cyclone movement. Tropical cyclones generate storm surges. Storm surges severely change the coastal environment, damage coastal structures, destroy forests and crops, inundate the coastline with saltwater and cause loss of lives. Due to overcrowding in the mainland in Bangladesh, poor and landless people live on the coast and they face frequent cyclones and associated surges. They affect food and drinking water and there is danger of transmission risks of infectious diseases, such as diarrhea, malaria, eye infections, skin diseases, etc. Some problems following a cyclone are usually created for their low literacy rate and poor knowledge of the environment. The tangible monitoring and warning of cyclones and associated surges should be given more priority for the region. The main objectives of this paper are to highlight the existing activities of the model in storm surges and related areas in the Bay of Bengal. We will explain the progress of a location-specific real-time standpoint prediction system for providing effective and timely surge forecasts. We will also introduce a model through numerical experiments using a severe cyclone in April 1991 to predict the storm surges that will be used to reduce economic losses and the number of deaths during a strong storm surge in the coastal area of Bangladesh.
\end{abstract}

Keywords: tropical cyclone; Bay of Bengal; storm surge; numerical modeling; coastal environment

\section{Introduction}

Storm surges are associated with severe weather such as tropical cyclones that constitute the world's most catastrophic natural disasters [1]. Among the most threatening calamities, storm surges stand out as the most damaging and undoubtedly as a cause of death and ruin as massive as that of earthquakes and tsunamis [2]. In history, low-lying deltaic regions of Bangladesh and Myanmar are heavily subjected to storm surge hazards. Fortunately, in most recent storm surge cases, the death toll is not as high as previously since the storm surge warning systems in fact worked well. However, we keep in mind that storm surges could be a cause of high death rates in the future while the number of residents is rising in coastal regions $[3,4]$. The key components contributing to calamitous surges in Bangladesh are as follows [5]:

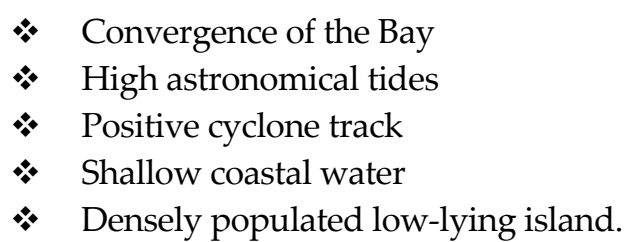


An updated and accurate storm surge prediction system is required to mitigate and prevent coastal disasters. It is essential to study local allocation characteristics exclusively along with previous storm surge heights in order to update the numerical forecast systems. Various ranges of motion must be investigated through numerical discrete structure of the governing equations to forecast surges in coastal areas exactly. It is also indispensable to examine long-term observation data perfectly in predicting the areas that storm surges might affect with precision [6-8]. As the landward boundary is approached, substantial grid refinement is typically required to resolve important schemes and prevent energy from aliasing. In providing an adequate resolution in the near shore region without increasing the size of the discrete problem, a numerical method must be used that permits a very high degree of grid flexibility.

\section{Materials}

\subsection{Model Equation}

The following depth-averaged vertically integrated form of the mass conservation equation, and the $x$ and $y$ components of the momentum equation, respectively, are used in investigating the dynamical process in the sea [6]:

$$
\begin{gathered}
\frac{\partial \xi}{\partial t}+\frac{\partial}{\partial x}[(\zeta+h) u]+\frac{\partial}{\partial y}[(\zeta+h) v]=0 \\
\frac{\partial u}{\partial t}+u \frac{\partial u}{\partial x}+v \frac{\partial u}{\partial y}-f v=-g \frac{\partial \xi}{\partial x}+\frac{T_{x}}{\rho(\xi+h)}-C_{f} \frac{u\left(u^{2}+v^{2}\right)^{1 / 2}}{\xi+h} \\
\frac{\partial v}{\partial t}+u \frac{\partial v}{\partial x}+v \frac{\partial v}{\partial y}+f u=-g \frac{\partial \xi}{\partial y}+\frac{T_{y}}{\rho(\xi+h)}-C_{f} \frac{v\left(u^{2}+v^{2}\right)^{1 / 2}}{\xi+h}
\end{gathered}
$$

In Equations (1)-(3), $x$ and $y$ are coordinate axes directed towards the south and east, respectively, where the origin is set at the northwest corner $\left(23^{\circ} \mathrm{N}, 85^{\circ} \mathrm{E}\right)$ of the computational $x y$-plane (Figure 1); $u$ and $v$ represent Reynold's averaged components of velocity in the $x$ and $y$ directions, respectively; $\zeta(x, y, t)$ is the displaced level of free surface of water above or below the mean sea level (MSL); $h(x, y)$ is the undisturbed water depth; $f(=2 \Omega \sin \phi$, where $\Omega$ is the angular speed of the earth rotation about its own axis, and $\phi$ represents the latitude of a position of interest) is the Coriolis parameter; $g\left(=9.81 \mathrm{~m} / \mathrm{s}^{2}\right)$ is the acceleration due to local gravity; $\rho$ is the sea water density, assumed to be uniform; $C_{f}(=0.0026)$ is the dimensionless bottom friction coefficient; $T_{x}$ and $T_{y}$ are the $x$ and $y$ components, respectively, of the wind stress acting on the sea surface.

The wind stress components mentioned above are derived following Ali [5] as

$$
\left(T_{x}, T_{y}\right)=\rho_{a} C_{D}\left(u_{a}^{2}+v_{a}^{2}\right)^{1 / 2}\left(u_{a}, v_{a}\right) .
$$

To derive the components of the wind stress, wind field is required. As in [7], the wind field is generated through the following formula:

$$
v_{a}= \begin{cases}V_{o} \sqrt{\left(r_{a} / R\right)^{3}}, & \text { for } r_{a} \leq R \\ V_{o} \sqrt{\left(R / r_{a}\right)^{3}}, & \text { for } r_{a}>R\end{cases}
$$

In Equations (4) and (5), $u_{a}$ and $v_{a}$ stand for the $x$ and $y$ components of the surface wind, respectively, $\rho_{a}$ is the air density, $C_{D}(=0.0028)$ is the surface drag coefficient, $V_{0}$ is the maximum sustained wind at the maximum radial distance $R$ and $r_{a}$ is the distance between the cyclone center and the point at which the wind field is desired. 


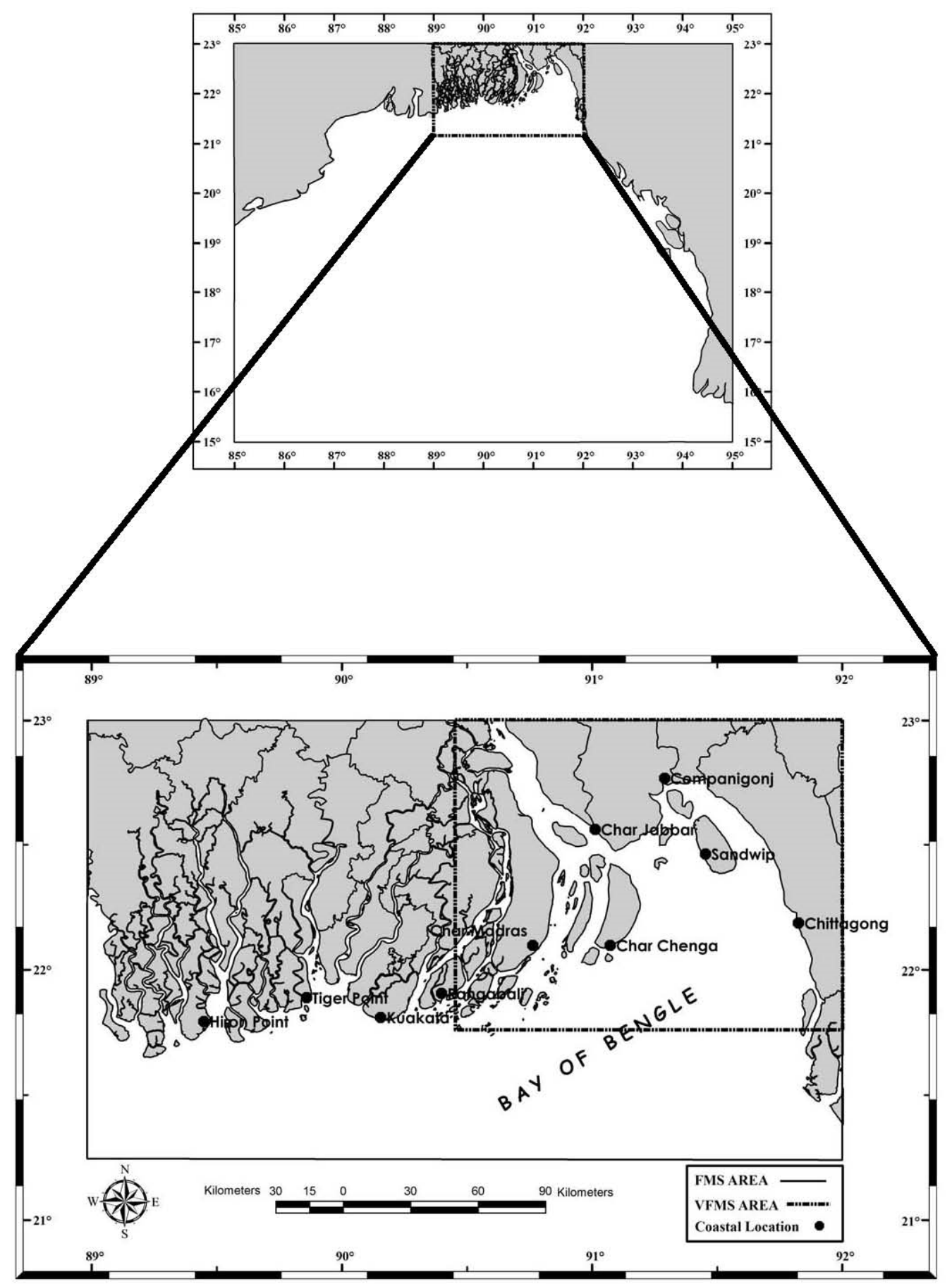

Figure 1. Domains of the three schemes CMS, FMS and VFMS and actual coastal and island boundaries along with ten representative locations at which computed results are presented (after Paul et al. [9]).

\subsection{Boundary Conditions}

The study domain has three open boundaries and one closed boundary. At the closed boundary (coastal or island boundary), the normal component of the depth averaged velocity is set to zero. Following Paul et al. [6], the western, eastern and southern open boundary conditions are, respectively, taken into account. These lead to

$$
v+(g / h)^{1 / 2} \zeta=0, v-(g / h)^{1 / 2} \zeta=0, u-(g / h)^{1 / 2} \zeta=-2 a(g / h)^{1 / 2} \sin \left(\frac{2 \pi t}{T}+\varphi\right),
$$


where $a, T$, and $\varphi$ stand for, respectively, the amplitude, period and phase of the tidal constituent under consideration.

Meghna River mouth is considered as open boundary and the freshwater discharge through the river is considered following Roy [7]. This leads to

$$
u_{b}=u+\frac{Q}{B(h+\xi)},
$$

where $Q$ denotes the volume of freshwater river discharge in a unit time and $B$ represents its width.

\subsection{Input}

In our study, we need several types of input. The meteorological input, namely maximum sustained wind radius, maximum sustained wind speed and storm track information are obtained from the Bangladesh Meteorological Department (BMD) through personal communication. The time varying positions of the storm and its nature are presented in Table 1 for a better understanding. The study also needs bathymetry data which is collected from the British Admiralty Chart. Shepard interpolation is used to supply water depth at the grid points of the three schemes, as we will see later, representing water. Further, the study needs tidal constants to generate a tidal response on the area of interest, which are taken from the study due to Paul et al. [6]. Following Paul et al. [9], the freshwater discharge through the river per unit time is taken as $Q=5100 \mathrm{~kg} / \mathrm{s}$ and the remaining parameters have been assumed to have their standard value.

Table 1. Time series for the positions and the nature of the April 1991 cyclone (Source: BMD).

\begin{tabular}{lcccc}
\hline Date (1991) & $\begin{array}{c}\text { Hour } \\
(\mathbf{U T C})\end{array}$ & $\begin{array}{c}\text { Latitude } \\
\left({ }^{\mathbf{}} \mathbf{N}\right)\end{array}$ & $\begin{array}{c}\text { Longitude } \\
\left(\mathbf{}^{\mathbf{E}}\right)\end{array}$ & Nature of the Storm \\
\hline 26 April & 1800 & 11.80 & 87.50 & Cyclonic storm \\
27 April & 0300 & 12.50 & 87.50 & Cyclonic storm \\
27 April & 0600 & 13.00 & 87.50 & Cyclonic storm \\
27 April & 0900 & 13.60 & 87.50 & Severe cyclonic storm \\
27 April & 1800 & 14.50 & 87.50 & Severe cyclonic storm with hurricane core \\
28 April & 0600 & 15.80 & 87.70 & Severe cyclonic storm with hurricane core \\
28 April & 0800 & 16.50 & 88.00 & Severe cyclonic storm with hurricane core \\
28 April & 1800 & 17.60 & 88.30 & Severe cyclonic storm with hurricane core \\
29 April & 0600 & 19.80 & 89.40 & Severe cyclonic storm with hurricane core \\
29 April & 1200 & 20.80 & 90.40 & Severe cyclonic storm with hurricane core \\
29 April & 1800 & 22.00 & 91.40 & Severe cyclonic storm with hurricane core \\
29 April & 2000 & 22.30 & 91.80 & Crossing the coast near Chittagong \\
30 April & 0000 & 23.00 & 92.40 & Crossed the Bangladesh coast \\
30 April & 0200 & 23.50 & 92.80 & -- \\
\hline
\end{tabular}

Maximum wind speed: $234 \mathrm{~km} \mathrm{~h}^{-1}$, maximum radius of sustained wind: $50 \mathrm{~km}$.

\section{Methodology}

\subsection{Numerical Procedures}

\subsubsection{Set-Up of Nested Scheme}

In order to incorporate the coastal complexity with minimum cost, a nested grid technique is used in this study. A high-resolution fine grid model, referred to as FMS, is nested into a scheme with relatively low resolution, which is referred to as CMS. It is of interest to note here that the FMS is designed to incorporate all the major offshore islands along the coast of Bangladesh. Now to incorporate properly the land-sea interface and bottom topographic detail of the Meghna estuarine area, which is referred to as the world's most vulnerable zone, a scheme with very high resolution is nested into the FMS. The innermost scheme is referred to as VFMS. To have a clear idea about the schemes, Figure 1 and Table 2 are inserted for a better perspective. It is to be noted here that Paul et al. [6] first used the 
MOL to solve shallow water equations in predicting water levels due to the tide-surge interaction along the coast of Bangladesh, where they used a nested grid technique without high resolution of grids. Thus, this study is an improvement on that of Paul et al. [6].

Table 2. Domains, grid resolutions and number of grid points of different schemes (after Paul et al. [9]).

\begin{tabular}{ccccc}
\hline Model & Domain Extent & $\begin{array}{c}\text { Grid Resolution } \\
\text { Along x-Axis }\end{array}$ & $\begin{array}{c}\text { Grid Resolution } \\
\text { Along y-Axis }\end{array}$ & Number of Grid Points \\
\hline CMS & $15^{\circ}-23^{\circ} \mathrm{N}$ and $85^{\circ}-95^{\circ} \mathrm{E}$ & $15.08 \mathrm{~km}$ & $17.52 \mathrm{~km}$ & $60 \times 61$ \\
FMS & $21.25^{\circ}$ and $89^{\circ}-92^{\circ} \mathrm{E}$ & $2.15 \mathrm{~km}$ & $3.29 \mathrm{~km}$ & $92 \times 95$ \\
VFMS & $21.77^{\circ}-23^{\circ} \mathrm{N}$ and $90.40^{\circ}-92^{\circ} \mathrm{E}$ & $720.73 \mathrm{~m}$ & $1142.39 \mathrm{~m}$ & $190 \times 145$ \\
\hline
\end{tabular}

\subsubsection{Discretization}

The aim of the study is to solve the governing equations with a numerical method of lines (MOL). It is of interest to note here that the method is efficient over the standard finite difference method due to having some benefits, especially, in computational coast, stability criterion, and simplicity in solving partial differential equations. Thus, in this regard, the equations and the boundary conditions are discretized only for spatial derivatives/variables by means of a semi-implicit three point central finite difference technique. We consider the discrete points in the $x y$-plane by defining $x_{i}=(i-1) \Delta x, i=1,2,3, \ldots, M$ (even), $y_{j}=(j-1) \Delta y, j=1,2,3, \ldots, N$ (odd).

If any dependent variable $\xi(x, y, t)$ at a grid point $\left(x_{i}, y_{j}\right)$ at time $t_{k}$ is represented by $\xi\left(x_{i}, y_{j}, t_{k}\right)=\xi_{i, j}^{k}$, then with the aid of the notations $0.5\left(\xi_{i+1, j}^{k}+\xi_{i-1, j}^{k}\right)={\overline{\xi_{i, j}^{k}}}^{x}$, $0.5\left(\xi_{i, j+1}^{k}+\xi_{i, j-1}^{k}\right)={\overline{\xi_{i, j}^{k}}}^{y}$ and $0.25\left(\xi_{i+1, j}^{k}+\xi_{i-1, j}^{k}+\xi_{i, j+1}^{k}+\xi_{i, j-1}^{k}\right)={\overline{\xi_{i, j}^{k}}}^{x y}$, one can discretize the equations of interest as follows.

For every grid point $\left(x_{i}, y_{j}\right)$, where $i=2,4,6, \ldots, M-2$ and $j=3,5,7, \ldots, N-2$, Equation (1) can be written as

$$
\left(\frac{\partial \zeta}{\partial t}\right)_{i, j}=f_{1}\left(\zeta_{l, m}^{k}, u_{l, m}^{k}, v_{l, m}^{k}, h_{l, m}\right)=C R 1+C R 1,
$$

where $l=i-1, i, i+1 ; m=j-1, j, j+1$;

$$
C R 1=-\frac{\left({\overline{\zeta_{i+1, j}^{k}}}^{x}+h_{i+1, j}\right) u_{i+1, j}^{k}-\left({\overline{\zeta_{i-1, j}^{k}}}^{x}+h_{i-1, j}\right) u_{i-1, j}^{k}}{2 \Delta x}, C R 2=-\frac{\left({\overline{\zeta_{i, j+1}^{k}}}^{y}+h_{i, j+1}\right) v_{i, j+1}^{k}-\left({\overline{\zeta_{i, j-1}^{k}}}^{y}+h_{i, j-1}\right) v_{i, j-1}^{k}}{2 \Delta y} .
$$

Again, for every point $\left(x_{i}, y_{j}\right)$, where $i=3,5,7, \ldots, M-1$ and $j=3,5,7, \ldots, N-2$, Equation (2) can be written as

$$
\left(\frac{\partial u}{\partial t}\right)_{i, j}=f_{2}\left(\xi_{l, m}^{k+1}, u_{l, m}^{k}, v_{l, m}^{k}, h_{l, m}\right)=U R 1+U R 2+U R 3+U R 4+U R 5+U R 6,
$$

where $l=i-2, i-1, i, i+1, i+2 ; m=j-2, j-1, j, j+1, j+2$ ； 


$$
\begin{aligned}
& U R 1=-\left\{\begin{array}{ll}
u_{i, j}^{k} \frac{u_{i+2, j}^{k}-u_{i-2, j}^{k}}{4 \Delta x}, & \text { for } i \neq m-1 \\
u_{i, j}^{k} \frac{0.5\left(3 u_{i, j}^{k}-u_{i-2, j}^{k}\right)-u_{i-2, j}^{k}}{4 \Delta x}, & \text { for } i=m-1
\end{array}, \quad U R 2=-\bar{v}_{i, j}^{k} x \frac{u_{i, j+1}^{k}-\bar{u}_{i, j-1}^{k}}{2 \Delta y}, U R 3=f_{i, j} \frac{v_{i, j}^{k}}{x y},\right. \\
& U R 4=-g \frac{\zeta_{i+1, j}^{k+1}-\zeta_{i-1, j}^{k+1}}{2 \Delta x}, \quad U R 5=\frac{T_{x}}{\rho\left({\overline{\zeta_{i, j}^{k+1}}}^{x}+h_{i, j}\right)}, \quad U R 6=-\frac{C_{f} u_{i, j}^{k}}{{\overline{\zeta_{i, j}^{k+1}}}^{x}+h_{i, j}}\left[\left(u_{i, j}^{k}\right)^{2}+\left({\overline{v_{i, j}^{k}}}^{x y}\right)^{2}\right]^{1 / 2},
\end{aligned}
$$

Finally, for every grid point $\left(x_{i}, y_{j}\right)$, where $i=2,4,6, \ldots, M-2$ and $j=2,4,6, \ldots, N-1$, Equation (3) can be written as

$$
\left(\frac{\partial v}{\partial t}\right)_{i, j}=f_{3}\left(\xi_{l, m}^{k+1}, u_{l, m}^{k}, v_{l, m}^{k}, h_{l, m}\right)=V R 1+V R 2+V R 3+V R 4+V R 5+V R 6,
$$

where $l=i-2, i-1, i, i+1, i+2 ; m=j-2, j-1, j, j+1, j+2$;

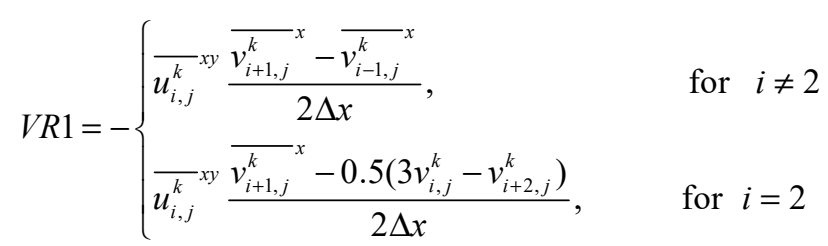

$$
\begin{aligned}
& V R 2=-\left\{\begin{array}{l}
v_{i, j}^{k} \frac{v_{i, j+2}^{k}-v_{i, j-2}^{k}}{4 \Delta y}, \quad \text { for } j \neq 2, j \neq n-1 \\
v_{i, j}^{k} \frac{v_{i, j+2}^{k}-0.5\left(3 v_{i, j}^{k}-v_{i, j+2}^{k}\right)}{4 \Delta y}, \text { for } j=2 \quad, V R 3=-f_{i, j} \overline{u_{i, j}^{k} x y}, V R 4=-g \frac{\zeta_{i, j+1}^{k+1}-\zeta_{i, j-1}^{k+1}}{2 \Delta y}, \\
v_{i, j}^{k} \frac{0.5\left(3 v_{i, j}^{k}-v_{i, j-2}^{k}\right)-v_{i, j-2}^{k}}{4 \Delta y}, \text { for } j=n-1 \\
V R 5=\frac{T_{y}}{\rho\left(\overline{\zeta_{i, j}^{k+1}}+h_{i, j}\right)}, \quad V R 6=-\frac{C_{f} v_{i, j}^{k}}{\overline{\zeta_{i, j}^{k+1} y}+h_{i, j}}\left[\left(\overline{u_{i, j}^{k} x y}\right)^{2}+\left(v_{i, j}^{k}\right)^{2}\right]^{1 / 2} .
\end{array}\right.
\end{aligned}
$$

The boundary conditions specified by Equation (6), the elevations at $j=1$ (eastern boundary), $j=N$ (western boundary and $i=M$ (southern boundary) are computed in the following manner, respectively:

$$
\begin{gathered}
\zeta_{i, 1}^{k+1}=-\zeta_{i, 3}^{k+1}-2 \sqrt{\left(h_{i, 2} / g\right)} \quad V_{i, 2}^{k} \\
\zeta_{i, N}^{k+1}=-\zeta_{i, N-2}^{k+1}+2 \sqrt{\left(h_{i, N-1} / g\right)} \quad V_{i, N-1}^{k}, \\
\zeta_{M, j}^{k+1}=-\zeta_{M-2, j}^{k+1}+2 \sqrt{\left(h_{M-1, j} / g\right)} \quad U_{M-1, j}^{k}+4 a \sin (2 \pi k \Delta t / T+\varphi),
\end{gathered}
$$

where $i=2,4,6, \ldots, M-2$ and $j=1,3,5, \ldots, N$.

The freshwater Meghna River discharge is incorporated through Equation (7), where the velocity component $U_{b}$ is calculated at $(1, j), j=7,9,11, \ldots, 19$ in the following manner:

$$
\left(U_{b}\right)_{1 . j}^{k+1}=\left(U_{b}\right)_{3, j}^{k+1}+\frac{Q}{\left(\zeta_{1, j}^{k+1}+h_{1, j}\right) B}
$$

\subsubsection{Working Procedure and Model Run}

Discretized form of Equations (8)-(10) are available in [6]. However, briefly they are inserted here for a better understanding. First Equation (8) is solved with $\mathrm{RK}(4,4)$ method 
for the elevation $\zeta$ at the internal (even, odd) grid points representing water of the CMS. Discretized BCs given by Equations (11)-(13) are then used to estimate $\zeta$ at the boundary (even, odd) grid points. An interpolation is then adopted to obtain $\zeta$ at the leftover grid points representing water and the land-sea interface. The wind field is then generated using Equations (4) and (5). Then Equation (9) is used for estimating $u$ at the interior (odd, odd) grid points representing water by inserting the parametric values involved and finally $v$ is evaluated in a similar fashion at the interior (even, even) grid points solving Equation (10). After computing $\zeta, u$, and $v$ in the CMS, the scheme is coupled with the FMS following a process found in [6] to have the boundary values from the CMS to run the FMS. In a similar manner, the VFMS is run with the boundary information from the FMS. Along the northern open boundary segment, $U_{b}$ is taken into account for the VFMS using Equation (14). This process is repeated over time providing the updated values of $\zeta, u$ and $v$ as initial conditions for computing WLs $(\zeta)$ owing to tide, surge and nonlinear interaction of tide and surge. For computing tide, surge and total water levels (water levels due to tide-surge interaction) all the models, namely tide, surge, and tide-surge interaction were run considering the time step as $\Delta t=60 \mathrm{~s}$ to ensure CourantFriedrich-Lewy (CFL) stability criterion. It is noteworthy that our model can run individually and simultaneously. The first tide model was run from the cold start ( $\zeta=0, u=0, v=0$ at $\mathrm{t}=0$ ) to get water levels with respect to the mean sea levels (MSL) considering the effect of $M_{2}$ tidal constituent along the southern open boundary of the CMS in the absence of meteorological forcing. A stable tidal oscillation was obtained after four tidal cycles of integration that provided the profile of the sea surface if the cyclone is not taken into account. In getting the pure surge level, the surge model (in absence of astronomical tide) was also run from the cold start. In achieving total WLs (due to the dynamic interaction of tide and surge), the tide model was run first. After having a stable tidal regime, the surge model was then made to run over it.

\section{Results and Discussion}

Water levels due to tide, surge and their interaction are calculated at the stations shown in Figure 1, but for the sake of brevity, the peak water levels due to surge and interaction of tide and surge are presented in Table 3 and the computed time series of water levels due to the tide, surge and the interaction of tide and surge are presented in Figure 2 with observed data. It is seen from Table 3 that our computed peak surge levels (water levels due to meteorological forcing only) along the region of interest vary between 2.97-6.51 m with $5.29 \mathrm{~m}$ at Chittagong. Paul et al. [6] predicted 3.52-6.70 m surge along the coast of Bangladesh. Further, according to BMD, the peak surge at Chittagong at the time of landfall was $5.50 \mathrm{~m}$. Thus, our computed surge level agrees well with the reported data by BMD at Chittagong and the simulated surge levels by Paul et al. [6]. Again, our computed peak total water levels were found to vary between $3.86 \mathrm{~m}$ (Kuakata) and $7.28 \mathrm{~m}$ (Companigonj), which agree fairly well with the results obtained in Paul et al. [6] (see Table 3). 
Table 3. Computed peak water levels simulated by the present study with respect to the mean sea level (MSL) and those obtained in [6].

\begin{tabular}{ccccc}
\hline & \multicolumn{2}{c}{ Present Study } & \multicolumn{2}{c}{ Study due to Paul et al. [6] } \\
\cline { 2 - 5 } Coastal Location & $\begin{array}{c}\text { Simulated Maxi- } \\
\text { mum Surge Level } \\
(\mathbf{m})\end{array}$ & $\begin{array}{c}\text { Simulated Maxi- } \\
\text { mum Total Water } \\
\text { Level (m) }\end{array}$ & $\begin{array}{c}\text { Maximum Surge } \\
\text { Level (m) }\end{array}$ & $\begin{array}{c}\text { Maximum Total } \\
\text { Water Level (m) }\end{array}$ \\
\hline Hiron point & 2.97 & 3.32 & 3.92 & 4.01 \\
Tiger point & 4.11 & 4.51 & 4.21 & 4.57 \\
Kuakata & 3.25 & 3.82 & 3.52 & 3.86 \\
Char Chenga & 5.70 & 5.89 & 5.11 & 5.81 \\
Char Jobbar & 6.12 & 6.33 & 6.19 & 6.35 \\
Companigonj & 6.51 & 6.30 & 6.70 & 7.28 \\
Sandwip & 5.40 & 5.71 & 5.24 & 5.63 \\
Chittagong & 5.29 & 5.79 & 5.17 & 6.26 \\
\hline
\end{tabular}

Our computed time series of water levels with respect to the MSL due to tide, surge and the interaction of tide and surge associated with the storm in April 1991 at Hiron Point, Char Chenga (Hatiya) and Chittagong are displayed in Figure 2. The corresponding observed data collected from Bangladesh Inland Water Transport Authority (BIWTA) are also presented in Figure 2. It is seen from Figure 2 that when the surge is away from the coast, the tide dominates the surge level; whether the opposite characteristics can be found when the surge is nearer to the coast as is expected. However, it is perceived from Figure 2 that our computed water levels due to the interaction of tide and surge are in good agreement with the data obtained from BIWTA.

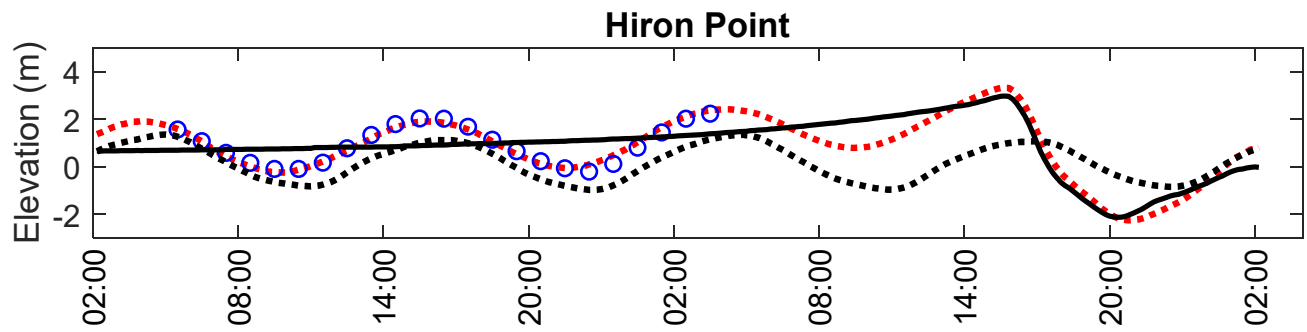

Char Chenga
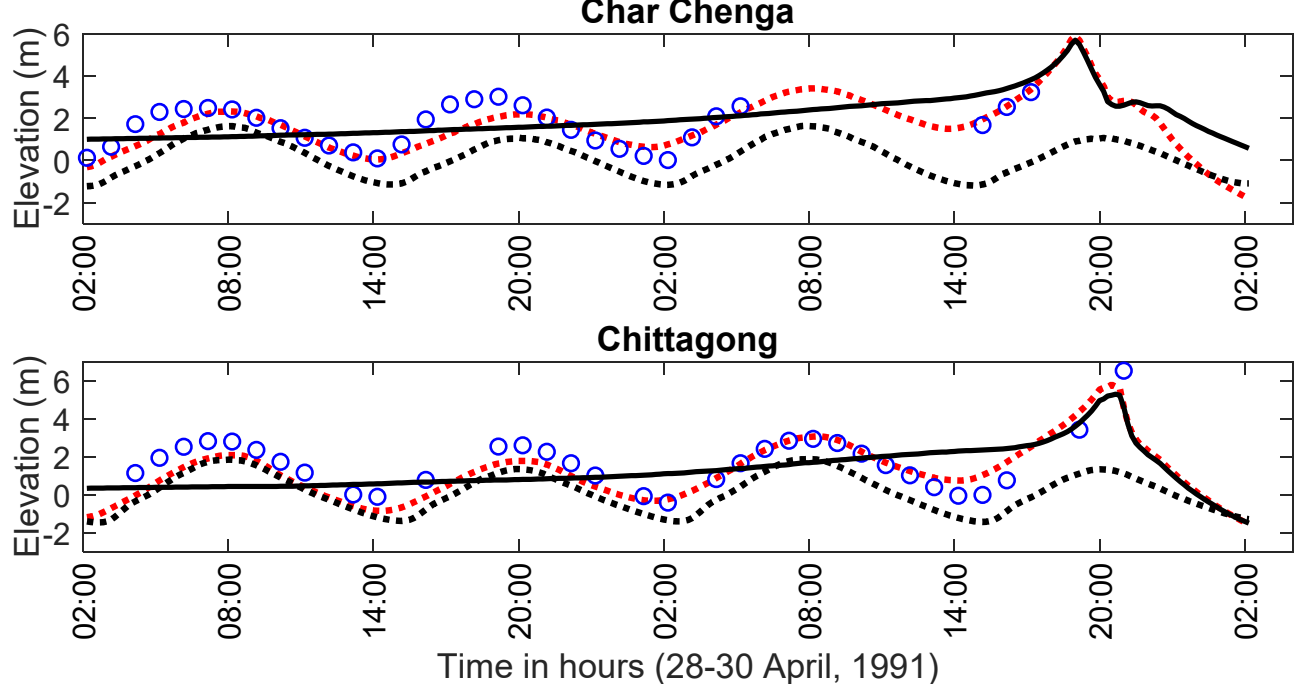

Figure. 2 Computed water levels with respect to the mean sea level due to tide, surge and their interaction with observed data at Hiron Point, Char Chenga and Chittagong. In each subplot, a black dotted curve represents the configuration for tide, black solid curve for surge, red dotted curve for tide-surge interaction, and a circle represents observed data. 
For validation of our simulated results, the root mean square analysis is carried out between the results attained in the study and observed data from BIWTA. The results that came out in this regard are presented in Table 4 . The root mean square error (RMSE) values obtained in this regard due to Paul et al. [9] are also presented in the same table for comparison. It is seen from Table 4 that the results attained by the study are considerable and comparable with those presented in [9].

Table 4. Estimated RMSEs in meters. The errors have been estimated between computed and observed water levels from 02.00 UTC of April 28 to 02.00 UTC of April 30 for the storm in April 1991. The observed data were obtained from BIWTA.

\begin{tabular}{ccc}
\hline Costal Station & Estimated by the Model & $\begin{array}{c}\text { Estimated by the Model Due to } \\
\text { Paul et al. [9] }\end{array}$ \\
\hline Chittagong & 0.78 & 0.73 \\
Char Chenga & 0.55 & 0.58 \\
Hiron Point & 0.18 & 0.16 \\
\hline
\end{tabular}

\section{Conclusions}

In this study, the MOL in coordination with the RK $(4,4)$ method is used to solve vertically integrated shallow water equations in Cartesian coordinates for simulating water levels along the coast of Bangladesh. The water levels due to the non-linear interaction of tide and surge associated with the cyclone in April 1991 are found to be in reasonable agreement with observed data from BIWTA on the basis of RMSE values. The outcome of this study thus can be utilized in practical forecasting.

Author Contributions: H.N. and G.P. conceived and designed the experiments and also analyzed the data. H.N. and G.P. completed the writing of the manuscript by sharing their knowledge and ideas and polished the paper through double checking. All authors have read and agreed to the published version of the manuscript.

Funding: This research received no external funding.

Institutional Review Board Statement: Not applicable.

Informed Consent Statement: Not applicable.

Data Availability Statement: The data were collected from Bangladesh meteorological Department and Bangladesh Inland Water Transport Authority.

Acknowledgments: Authors would like to articulate their heartfelt thanks to the Department of Mathematics and Natural Sciences, Brac University, Dhaka, Bangladesh for providing suitable research facilities. Moreover, authors take pleasure in expressing their genuine appreciation to the anonymous referees for their significant comments and suggestions.

Conflicts of Interest: The authors declare no conflict of interest.

\section{References}

1. Dube, S.K.; Rao, A.D.; Sinha, P.C.; Murty, T.S.; Bahulayan, N. Storm surge in the Bay of Bengal and Arabian Sea the problem and its prediction. Mausam 1997, 48, 283-304.

2. Li, J.; Nie, B. Storm surge prediction: Present status and future challenges. Procedia IUTAM 2017, 25, 3-9.

3. Kohno, N.; Dube, S.K.; Entel, M.; Fakhruddin, S.H.M.; Greenslade, D.; Leroux, M.D.; Thuy, N.B. Recent progress in storm surge forecasting. Trop. Cyclone Res. Rev. 2018, 7, 128-139.

4. Lynch, D.R. Progress in hydrodynamic modeling, review of U.S. contributions, 1979-1982. Rev. Geophys. Space Phys. 1983, 21, 741-754.

5. ALI, A. Storm Surges in the Bay of Bengal and Some Related Problems. Ph.D. Thesis, University of Reading, Reading, UK, 1979; p. 227.

6. Paul, G.C.; Ismail, A.I.M.; Karim, M.F. Implementation of method of lines to predict water levels due to a storm along the coastal region of Bangladesh. J. Oceanography 2014, 70, 199-210.

7. Roy, G.D. Estimation of expected maximum possible water level along the Meghna estuary using a tide and surge interaction model. Environ. Int. 1995, 21, 671-677. 
8. Naher, H.; Paul, G.C. Further Development of Forecasting Model for Storm Surge Hazard along the Coast of Bangladesh. Am. J. Environ. Prot. 2019, 7, 52-55.

9. Paul, G.C.; Ismail, A.I.M.; Rahman, A.; Karim, M.F.; Hoque, A. Development of tide-surge interaction model for the coastal region of Bangladesh. Estuaries Coasts 2016, 39, 1582-1599. 